\title{
Development and Analysis of Prefabricated Concrete Buildings in Chengdu, China
}

\author{
Gang Yao ${ }^{1,2}$, Mingpu Wang ${ }^{1,2}$, Yang Yang ${ }^{1,2^{*}}$, Jun $\mathrm{Li}^{1,2}$ \\ ${ }^{1}$ Key Laboratory of New Technology for Construction of Cities in Mountain Area, Ministry of Education, Chongqing 400045, \\ China \\ ${ }^{2}$ School of Civil Engineering, Chongqing University, Chongqing, 400045, China
}

Corresponding Author Email: 20121601009@cqu.edu.cn

https://doi.org/10.18280/ijsdp.150318

Received: 20 April 2019

Accepted: 11 December 2019

\section{Keywords:}

prefabricated concrete buildings, urbanization, industrialization, city planning

\begin{abstract}
Prefabricated construction is an inevitable trend in the reform of modern construction, playing an important role in sustainable development and conserving resources. Based on field investigation, questionnaire survey, and the collection and analysis of relevant data, the prefabricated concrete buildings of Chengdu (China) were researched. The development status of prefabricated concrete buildings, production base of prefabricated components, price of precast concrete, and the scale of building construction industry were analyzed and studied. The development obstacles of the prefabricated concrete building were presented and relevant suggestions were provided. The research shows that the production base of prefabricated component is reasonably laid out by forming a radiation circle with the reasonable radius. The price of the prefabricated component is controlled by the average reduction of 1039.8 yuan $/ \mathrm{m}^{3}$, and the proportion of prefabricated concrete buildings is adjusted by an increase of $8 \%$ to $10 \%$ per year. This can promote the development of prefabricated concrete buildings in Chengdu. The incomplete standardization system is the most serious development obstacle, and the establishment of local standards is an effective development proposal. This research provides a reference for the development of prefabricated concrete buildings in large and medium-sized cities.
\end{abstract}

\section{INTRODUCTION}

At present, the construction industry in China is developing rapidly, and the scale of construction is increasing, but the construction method is still dominated by traditional cast-inplace. The traditional cast-in-place construction method is high in consumption, pollution, and low in efficiency. Therefore, it is imperative to develop a new construction method that is conducive to industrialization of buildings and sustainable development of city [1]. Vigorously developing prefabricated construction is the way for the sustainable development of construction industry in China [2]. It is found that prefabricated construction can promote the supply-side structural reform of the construction industry and accelerate the process of new urbanization [3].

Compared with some developed countries, the prefabricated construction in China is still in the initial stage of development [4]. Prefabricated construction is commonly and reasonably used in USA, Sweden, Japan, and UK [5]. Prefabricated construction received a boost in 2004 when the UK housing sector took initiative to construct at least $25 \%$ of the new social housing using off-site construction techniques [6]. In recent years, the prefabricated construction has attracted significant attention due to its advantages over traditional construction methods. The research on prefabricated concrete buildings started in the 1950s. These countries have a large number of achievements in technologies, standards, and specifications [7, 8]. The cost, resources, and methods of prefabricated construction have been mainly studied [9-11]. Due to the development of prefabricated construction, the structural form, structural response, transportation, and supply chain configurations of prefabricated components have also received much attention [12-15]. In addition to structural components of the building, prefabricated technology has been extended to other repetitive component units including shield tunnel segments, retaining walls, railway sleepers and so on [16-18]. With the development of technology and the acceleration of urbanization, the global prefabricated construction market is growing [5]. The future prospects of prefabricated construction are excellent.

Since 2013, a lot of researches have been done on prefabrication technology, prefabricated project management, and prefabricated components in China. However, there is a lack of research on prefabricated construction with the local characteristics [19]. Prefabricated buildings are classified into concrete structure, steel structure, and wood structure according to the type of structure. At present, the prefabricated concrete structure is the main structural type of prefabricated construction in China and the focus of prefabrication-related researches. In order to promote the development of prefabricated concrete buildings in China, it is very important to analyze the current status of typical urban prefabricated concrete buildings and to study their development plans. Chengdu is an important city in the southwest of China and one of the pilot cities for prefabricated construction. It is one of the typical large-scale cities in China with rapid development. The development of the prefabricated construction industry in Chengdu may provide a good 
reference for other cities.

This research takes Chengdu as an example to analyze its prefabricated concrete buildings. Through field investigation and questionnaire survey, the development status of prefabricated concrete buildings, production base of prefabricated components, price of precast concrete, and the scale of building construction industry are analyzed and studied. Based on these analyses and researches, the development obstacles of the prefabricated concrete building are presented and relevant suggestions are provided. The outcome of this research will help employees in the prefabricated construction industry chain acquire new knowledge and critical information. This research provides a reliable reference for the development of prefabricated concrete buildings in large and medium-sized cities.

\section{DEVELOPMENT OF PREFABRICATED CONCRETE BUILDINGS IN CHENGDU}

The area of Chengdu is 14,600 square kilometers, the resident population is more than 16 million, and the urbanization rate is $70.6 \%$. It is in the stage of accelerating urbanization. The growth trend of urbanization rate in Chengdu is shown in Figure 1.

The prefabricated construction in Chengdu has developed rapidly with the advancement of urbanization. The prefabricated concrete buildings in Chengdu began to develop in 2011 and the momentum is good. From 2011 to 2018, it can be divided into three stages: initial test stage, demonstration stage, and promotion stage. From 2011 to 2014, the prefabricated concrete building industry in Chengdu is in the initial test stage and there are few types of concrete prefabricated components. The experiment and research on its design and production just began [20]. From 2015 to 2016, the prefabricated concrete building industry is in the demonstration stage. The prefabricated construction base and the prefabricated construction demonstration project were vigorously promoted in China. In 2015, the prefabricated construction pilot projects were gradually launched in Chengdu. In 2016, the prefabricated construction project expanded from the affordable housing to municipal facilities and commercial housing. Since 2017, the prefabricated concrete building industry in Chengdu is in the promotion stage. In 2017, there were five prefabricated component production bases in Chengdu, and 19 related technical standards. There were 13 prefabricated construction projects, and prefabricated construction area of over 3 million square meters. In 2018, the prefabricated commercial residential building totally started, and the rail transit project gradually realized prefabrication.

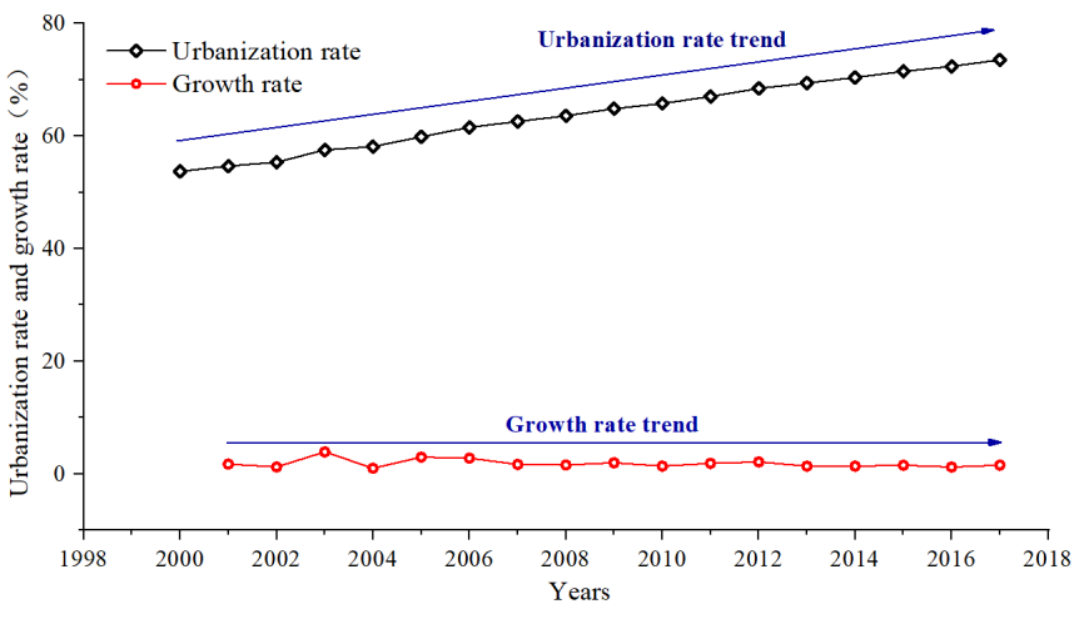

Figure 1. Chengdu Urbanization Rate from 2000 to 2017

\section{PRODUCTION BASE OF PREFABRICATED COMPONENTS}

In the development process of prefabricated construction, there is a general phenomenon that the integration degree of industrial china is low. By the production base of prefabricated components, the construction, design, developer and component producers can be effectively linked [21]. To build a complete prefabricated construction industry chain, thereby speeding up the process and reducing costs [22]. At present, there are five production bases of prefabricated components in Chengdu [23]. The area and production capacity are shown in Table 1. The geographical location and radiation range are shown in Figure 2.

Table 1. Area and production capacity of production bases of prefabricated components in Chengdu

\begin{tabular}{ccc}
\hline Construction Industrialization Production Base & Area $\left.\mathbf{( m}^{\mathbf{2}}\right)$ & Production capacity $\left(\mathbf{m}^{\mathbf{3}}\right)$ \\
\hline 1. Chengdu Construction Group & 180,000 & 150,000 \\
2. China Construction Science \& Technology Chengdu Group & 100,000 & 200,000 \\
3. Chengdu Broad Construction Technology Group & 160,000 & 300,000 \\
4. Chengdu Chengtou Group & 240,000 & 300,000 \\
5. Power China Chengdu Group & 310,000 & 300,000 \\
\hline
\end{tabular}




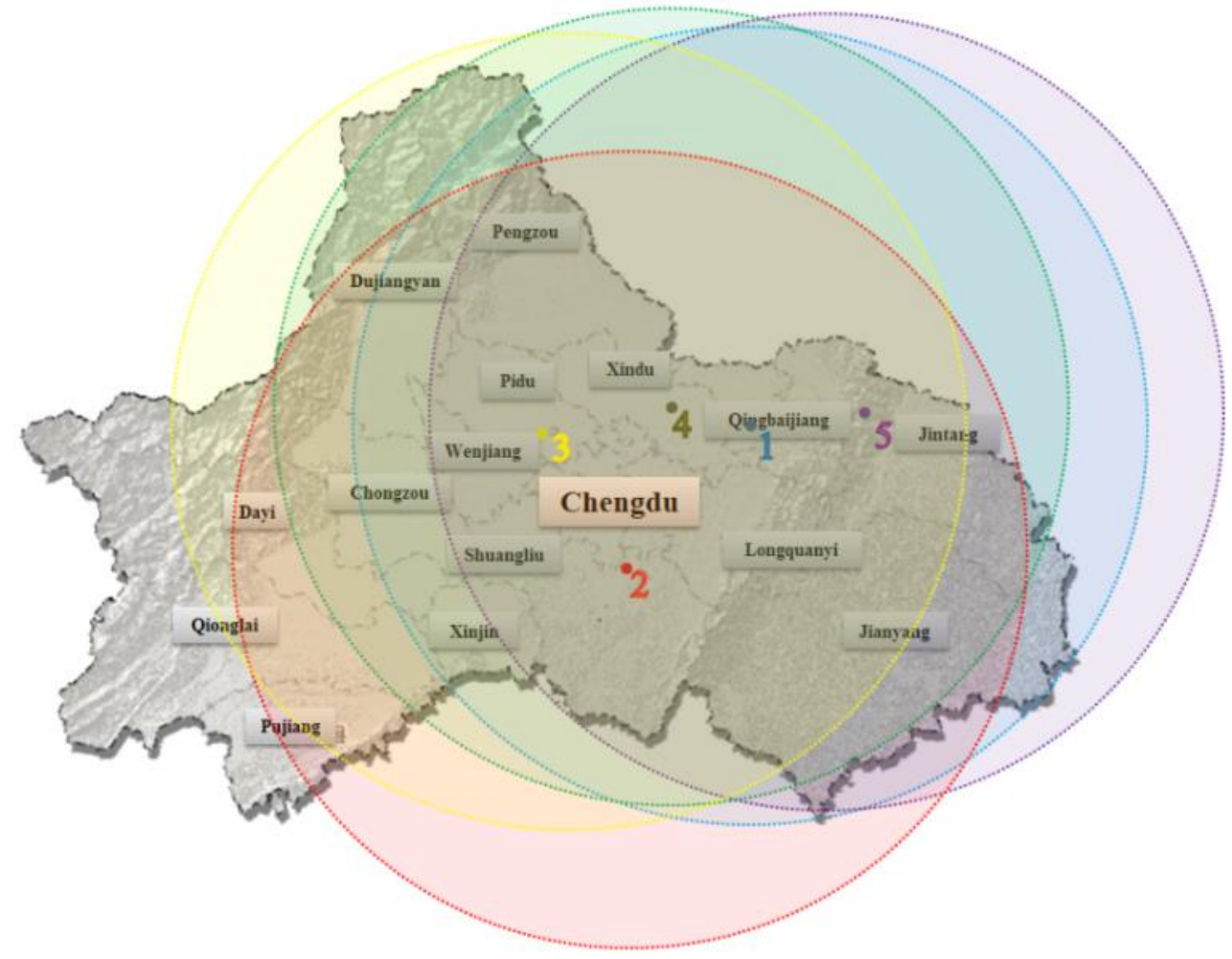

Figure 2. Layout and radiation range of production bases of prefabricated components in Chengdu

The production bases indicated by the serial numbers in Figure 2 are shown in Table 1. It can be seen from Figure 2 that the production bases of prefabricated components in Chengdu is evenly distributed around the main city. The reasonable transportation radius of the prefabricated components is about $90 \mathrm{~km}$. The reasonable transportation radius is estimated by reasonable transportation costs accounting for $8 \%$ of sales of the prefabricated component [24]. According to the "Prefabricated Component Reference Price in Chengdu", the average price of various prefabricated components in Chengdu is 3133.34 yuan $/ \mathrm{m}^{3}$, and the transportation costs of $1 \mathrm{~km}$ is 2.76 yuan $/ \mathrm{m}^{3}$. The reasonable transportation radius of production base of prefabricated components in Chengdu is estimated to be $90 \mathrm{~km}$ by the above method and data. Except Dayi County, Pujiang County and Qionglai County, the other districts are covered by the radiation range of the five production bases. In 2018, Jiaotou Construction Industrialization Co., Ltd. Qionglai prefabricated component production base was established but not put into production. Plus the radiation range of this production base, Chengdu will be fully covered.

By 2020, new municipal infrastructure, rail transit, and commercial residential buildings in Chengdu require a large number of prefabricated components. It is estimated that the demand for prefabricated components is about 1 million $\mathrm{m}^{3}$ per year in Chengdu [25]. At present, the prefabricated component production base in Chengdu has a reasonable layout, with a total design production capacity of 1.25 million $\mathrm{m}^{3}$ per year meeting the construction needs from 2018 to 2020 . After 2020, it is necessary to build more prefabricated component production bases with the annual design capacity of more than $300,000 \mathrm{~m}^{3}$ to increase the production capacity. The scale and number of component production bases should be determined with reference to the projects under construction and the proposed projects. So as to carry out the layout of the production base of prefabricated components, taking the production base as the center, the radiation circle is formed with the reasonable transportation radius. The reasonable radiation circle should cover the entire city and minimize the overlapping areas.

\section{PRICES OF PRECAST CONCRETE COMPONENT}

At present, the price of precast concrete (PC) components is high, which hinders the development of prefabricated concrete buildings [9]. There are many types of PC components, resulting in high design costs and high mold costs. Compared with traditional cast-in-place reinforced concrete, the proportion of concrete and steel bars of PC components is high, and the cost of materials is high [26]. PC components are subject to a $17 \%$ value added tax. The general PC components are bulky and inconvenient to transport, resulting in an increase in transportation costs [27].

The cost of prefabricated concrete buildings is higher than that of cast-in-place concrete buildings. Take the rectangular beam as an example to compare and analyze the price of the two. The PC component reference price is 3506.9 yuan $/ \mathrm{m}^{3}$ in Chengdu. The arrival price includes all costs such as steel, concrete, transportation, management fees, profits and taxes [28]. The price of cast-in-place beam is estimated by the market price of each item. The comparison of the price of PC components and cast-in-place concrete in Chengdu is shown in Table 2.

It can be seen from Table 2 that the arrival price of the PC components is much higher than that of the cast-in-place concrete, and the price difference between the two is 2013.4 yuan $/ \mathrm{m}^{3}$. The average price difference between conventional PC components such as rectangular beams and rectangular columns and cast-in-place concrete is 1630.8 yuan $/ \mathrm{m}^{3}$. Mold costs, machinery depreciation, transportation costs, management costs and taxes mainly cause the price gap. The 
on-site construction costs of PC components are lower than that of cast-in-place concrete, and there are government policy support and financial subsidies on PC components. These can narrow the gap between the two prices by about 600 yuan $/ \mathrm{m}^{3}$, but there is still a big price gap. Reasonable layout of production base can reduce transportation costs, and the prefabricated technology standards can improve mold utilization and reduce mold costs and design costs. With an average reduction of 1039.8 yuan $/ \mathrm{m}^{3}$ as the goal, control the price of PC components, can further promote the development of prefabricated concrete buildings.

Table 2. Comparison of the price of PC components and cast-in-place concrete

\begin{tabular}{ccc}
\hline Item & $\begin{array}{c}\mathbf{P C} \\
\left(\mathbf{y u a n} / \mathbf{m}^{\mathbf{3}}\right)\end{array}$ & $\begin{array}{c}\text { Cast-in-place } \\
\left(\mathbf{y u a n} / \mathbf{m}^{\mathbf{3}}\right)\end{array}$ \\
\hline Concrete & $/$ & 350 \\
Steel bar & $/$ & 300 \\
Mold & $/$ & 250 \\
Insulation & $/$ & 200 \\
Plastering & $/$ & 150 \\
Remaining expenses & $/$ & 200 \\
Tax & 509.6 & 43.5 \\
Arrival price (including tax $)$ & 3506.9 & 1493.5 \\
\hline
\end{tabular}

\section{SCALE OF BUILDING CONSTRUCTION INDUSTRY}

From the data of "Chengdu Statistical Yearbook, the area of residential construction in Chengdu maintained a steady growth trend from 1978 to 2015. After 1998, due to the acceleration of urbanization in China, the area of residential construction increased significantly [29]. After 2015, the Chengdu government adjusted the real estate industry, which led to a slight decline in the area of residential construction in Chengdu. At present, the development of prefabricated concrete buildings in Chengdu depends largely on the residential construction, so the research on the residential construction in Chengdu is necessary.

\subsection{Residential construction research}

The statistical information on the area of residential construction in Chengdu is mainly from the "Overall Social Housing Buildings" in the "Chengdu Statistical Yearbook". The development trend of residential construction area and completed area in Chengdu from 1997 to 2016 is shown in Figure 3.

As can be seen from Figure 3, the residential construction area of Chengdu from 1997 to 2016 is on the rise, with a rapid increase from 2005 to 2009. The urbanization and residential construction industry in Chengdu developed rapidly at that time. From 2012 to 2016, the residential construction area is in a stable state, which is closely related to the government's regulation and control. It can be predicted that the residential construction area will be stable or slightly rising from 2018 to 2025. With the increase in the area of residential construction in Chengdu, the traditional construction industry needs to transform to the modern construction industry. The promotion and development of prefabricated concrete buildings is significant.

\subsection{Analysis of the proportion of prefabricated concrete buildings}

The development goal of prefabricated construction in Chengdu is that the proportion of new prefabricated construction area to new total construction area in Chengdu is more than $35 \%$ by 2020 . The prefabricated construction area data comes from the "Chengdu Statistical Yearbook". The proportion of new prefabricated concrete buildings area to new total construction area per year in Chengdu is shown in Figure 4.

It can be seen from Figure 4 that the prefabricated concrete buildings account for an increasing proportion of new buildings. From 2012 to 2014, the average construction area of new buildings in Chengdu is 7097 million $\mathrm{m}^{2}$ per year, and the proportion of prefabricated concrete buildings area is less than $0.1 \%$. From 2015 to 2016 , the upward trend is obvious. This is closely related to the policy support of Chengdu government. The average construction area of new buildings in Chengdu is 6961.5 million $\mathrm{m}^{2}$ per year, and the proportion of prefabricated concrete buildings area is $1.4 \%$. From 2017 to the present, there are 13 prefabricated construction projects in Chengdu with the construction area of over 3 million $\mathrm{m}^{2}$. In 2017 , the proportion of prefabricated concrete buildings area was $4.22 \%$.

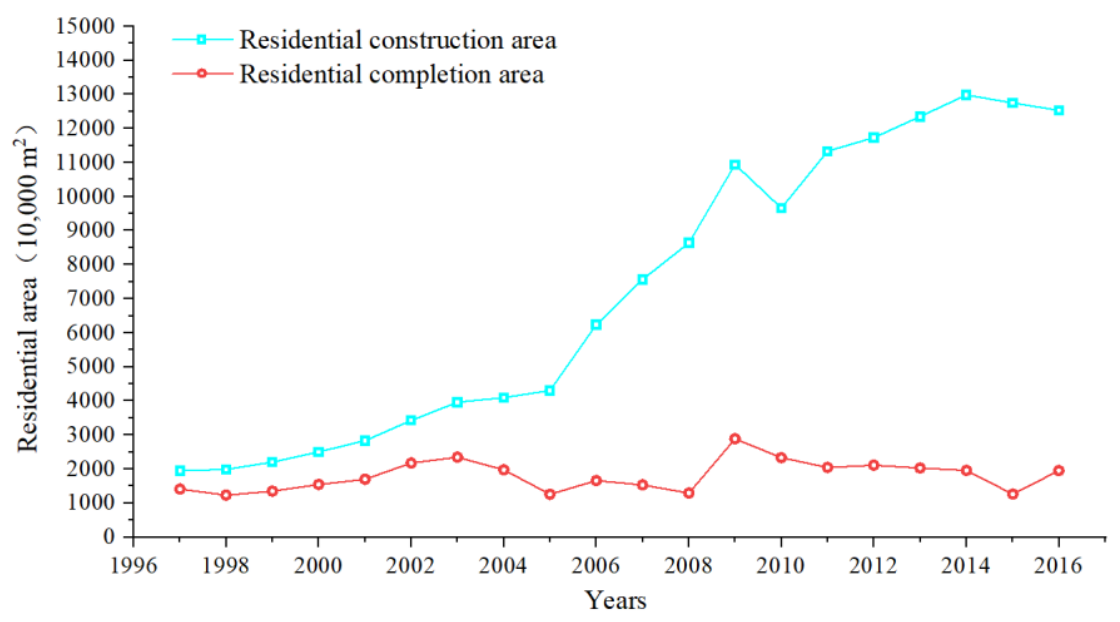

Figure 3. Construction and completion area of residential buildings in Chengdu from 1997 to 2016 


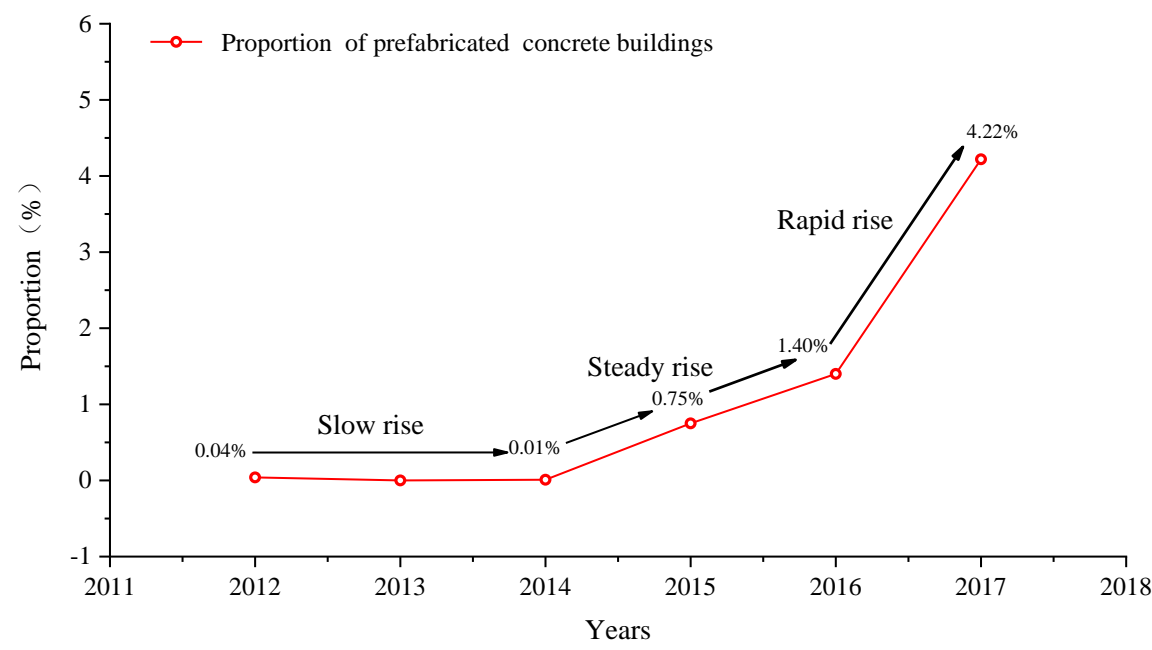

Figure 4. Proportion of new prefabricated concrete buildings area to new total construction area in Chengdu from 2012 to 2017

At present, the proportion of prefabricated concrete buildings in Chengdu is at medium level in China, with a good development momentum. The trend of residential construction area and completed area of Chengdu are stable. According to the increasing trend of the proportion of prefabricated concrete buildings, it is expected that Chengdu municipal government could dynamically adjust the proportion of prefabricated concrete buildings by an increase of $8 \%-10 \%$ per year, to maintain stable development status.

\section{DEVELOPMENT OBSTACLES AND SUGGESTIONS FOR PREFABRICATED CONCRETE BUILDINGS IN CHENGDU}

The prefabricated construction industry in Chengdu is in a stage of rapid development, with certain development advantages, such as reducing environmental pollution, shortening construction period, and reducing labor. But at the same time there are certain obstacles to its development [30]. In order to study the obstacles to the development of prefabricated construction in Chengdu, expert symposium was held to collect opinions. Based on the analysis of the first four chapters, combined with other study $[9,31]$, the questionnaire was produced to collect relevant data and make analysis. The background of the participants is reasonable, and the organization and number of the participants are shown in Table 3.

Table 3. Organization and number of the participants

\begin{tabular}{ccc}
\hline Organization & Number & Percentage \\
\hline Government agency & 2 & $15.4 \%$ \\
Design institute & 2 & $15.4 \%$ \\
University & 3 & $23.1 \%$ \\
Component production base & 3 & $23.1 \%$ \\
Construction contractor & 2 & $15.4 \%$ \\
Building developer & 1 & $7.7 \%$ \\
Total & 13 & $100 \%$ \\
\hline
\end{tabular}

\subsection{Obstacles to the development of prefabricated concrete buildings in Chengdu}

Six obstacles to the development of prefabricated concrete buildings in Chengdu were screened out and the questionnaires were designed [32]. The first part of the questionnaire is collecting basic information and the second part is the six main developmental obstacles. The obstacles to development are: (1) imperfect specification and standard system, (2) difficulty in design change, (3) difficulty in components transportation, (4) lack of professional talents, (5) high cost of prefabricated construction, and (6) imperfect supporting industry chain. Fill in the questionnaire to score the obstacle degree of each option, 3 points means that this obstacle seriously hinders the development of prefabricated concrete buildings, 2 points means hindering its development, 1 point means slightly hindering its development, 0 point means that this obstacle does not hinder its development.

The data was collected in the form of on-site questionnaires. 84 people filled out the questionnaires and 84 valid questionnaires were collected. The scale of the questionnaire satisfies the requirements of statistical analysis and the background of the respondents is reasonable. The organization and number of the respondents are shown in Table 4. The questionnaire statistics of each obstacle are shown in Figure 5 and Figure 6.

Table 4. Organization and number of the respondents

\begin{tabular}{ccc}
\hline Organization & Number & percentage \\
\hline Government agency & 6 & $7.1 \%$ \\
Design institute & 14 & $16.7 \%$ \\
University & 18 & $21.4 \%$ \\
component production base & 22 & $26.2 \%$ \\
Construction contractor & 19 & $22.6 \%$ \\
Building developer & 5 & $6.0 \%$ \\
total & 84 & $100 \%$ \\
\hline
\end{tabular}

From the results shown in Figure 5 and Figure 6, the standard deviation of the statistical results of the six obstacle factors is greater than 0.6. The main reason is that the background of the questionnaire is different, and the views on each option are different. However, the standard deviations are all less than 0.9, the degree of dispersion is within an acceptable range, and the average value can represent the obstacles degree of various factors. Except for the "lack of professional talents", the average of the other five factors is greater than 2 points, which indicates that most of the questionnaires consider these five factors to be the main obstacles to the development of prefabricated construction in Chengdu. 


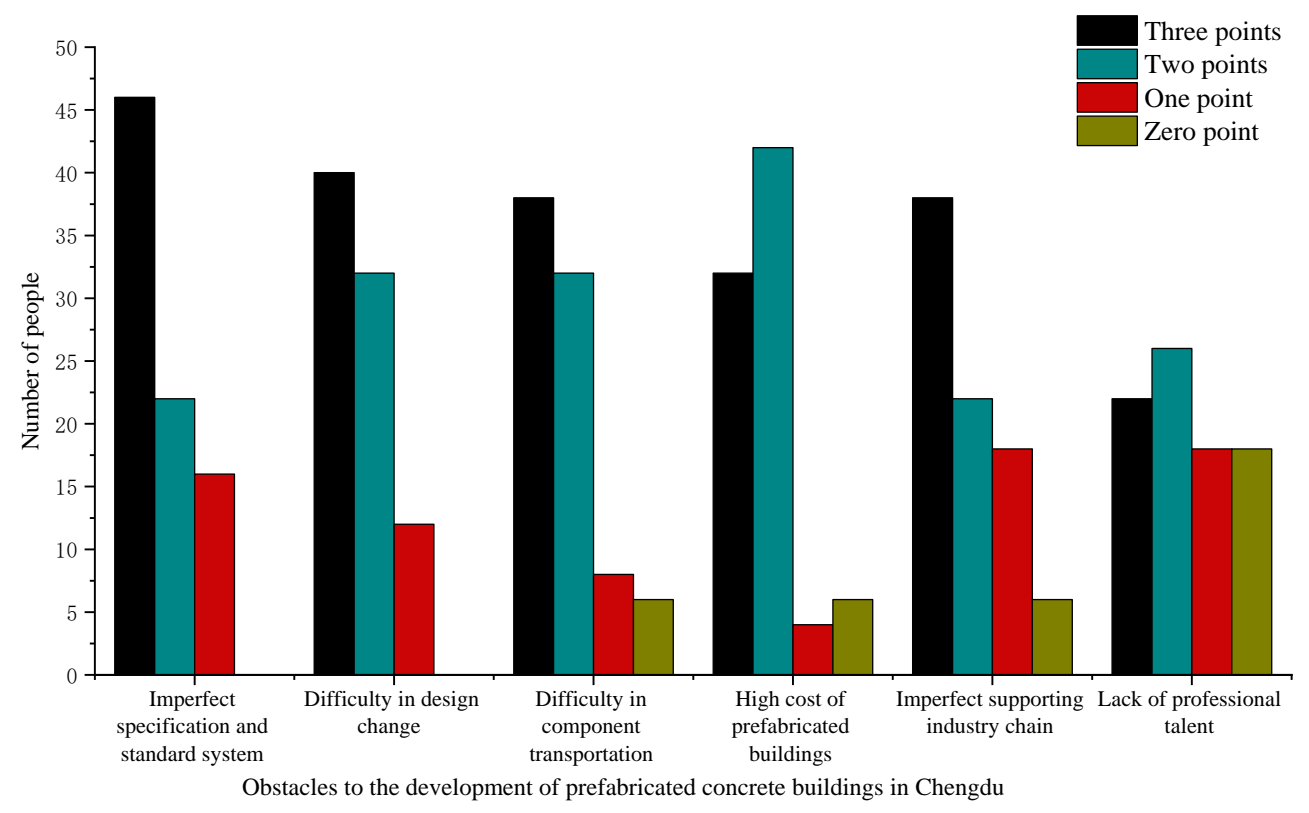

Figure 5. Score statistics of development obstacle to prefabricated concrete buildings in Chengdu

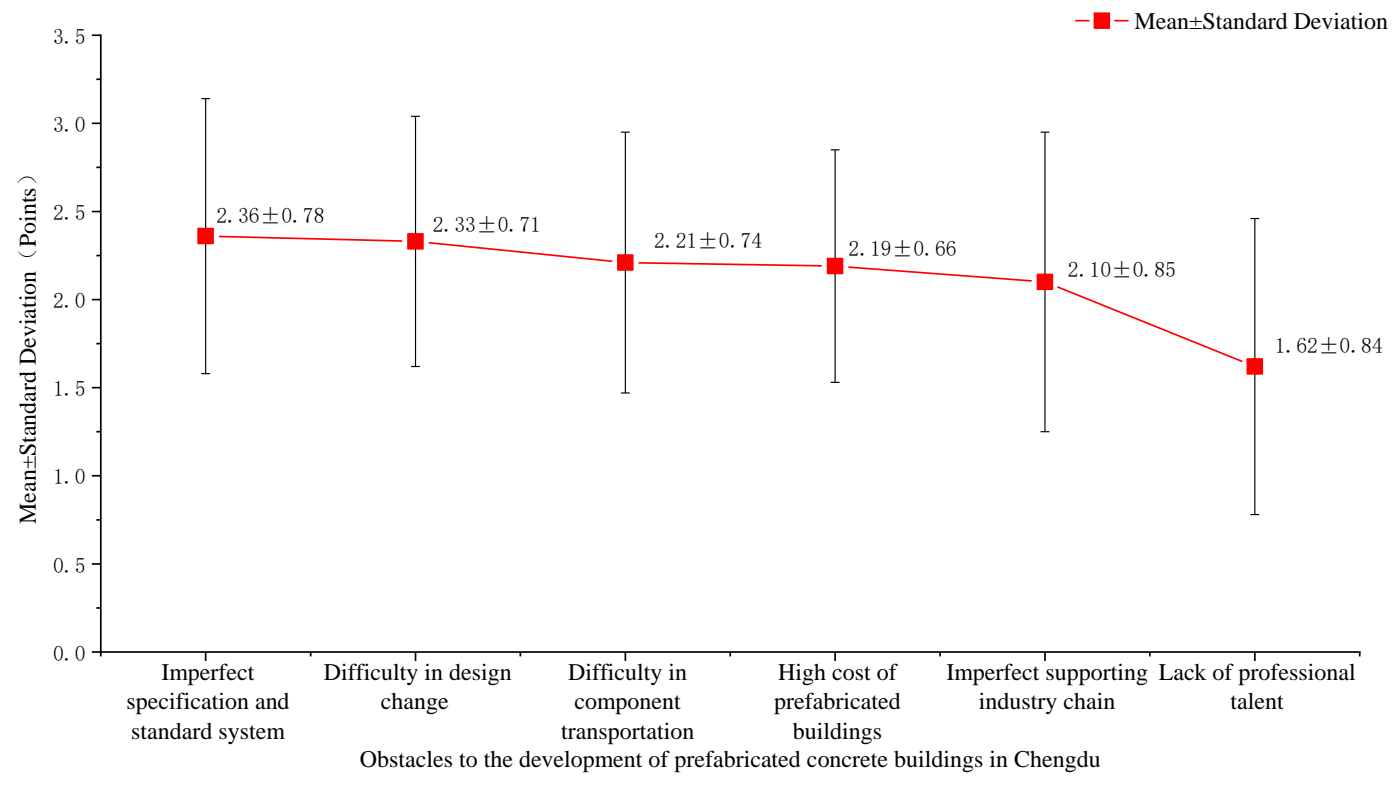

Figure 6. Mean and standard deviation of development obstacle scores

The "imperfect specification and standard system" scoring $2.36 \pm 0.78$ is considered to be the most important development obstacle. At the expert symposium, some participants suggested that the imperfect standard system and the lack of application of information technology are the main reasons for the uncoordinated modularization of the prefabricated building market and the low integration of parts. Some large enterprises use their own design software and parts library to design. Although they can meet the production needs of individual projects, but it is not conducive to the standardization of parts and components, and fostering sustainable prefabricated construction market.

The "difficulty in design change" scores $2.33 \pm 0.71$. The design change is common during the construction. Due to low standardization, some design changes can significantly increase production costs. The "difficulty in components transportation" scores $2.21 \pm 0.74$. Some kinds of prefabricated components are large in volume and quantity, and difficult to transport. The "high cost of prefabricated construction" scores
$2.19 \pm 0.66$. The components have higher tax rates, and the production costs and transportation costs are high. In order to ensure own interests of enterprises, the prices of the prefabricated construction will increase. The "imperfect supporting industry chain" scores $2.19 \pm 0.66$. There are many related industries involved in the prefabricated construction, and its development requires the cooperation of various industries. Few design institutes and construction contractors focus on the field of prefabricated construction, which is not conducive to technological innovation. Some traditional enterprises face the challenge of changing the traditional construction methods. The willingness of traditional enterprises to transform and develop is not strong.

The "lack of professional talents" scores $1.62 \pm 0.84$, which is the lowest. At the symposium, some participants proposed that the prefabricated construction is a new type of construction. At present, most design units are not deeply researching on prefabricated construction, and the design is difficult to meet customer requirements. Prefabricated 
construction has high requirements on construction quality and precision. The nomadic construction team is not conducive to the formation of a group of construction technicians with strong professional skills. However, other participants believe that the technicians with traditional construction and design foundations can quickly become professionals in the prefabricated construction industry with the efforts of all parties.

\subsection{Suggestions for the development of prefabricated concrete buildings in Chengdu}

The third part of the questionnaire is six suggestions for the development of prefabricate buildings in Chengdu: (1) develop prefabricated technology, (2) establish local standards, (3) formulate transportation incentives, (4) train talents, (5) establish prefabricated construction industrial parks, and (6) increase publicity and promotion. Fill in the questionnaire to score the expected effectiveness of the suggestions, 3 points means that this suggestion is very effective for the development of prefabricated concrete buildings, 2 points means effective for its development, 1 point means slightly effective for its development, 0 point means that this suggestion is invalid for its development. The questionnaires statistics on the effectiveness of the development suggestions are shown in Figure 7 and Figure 8.

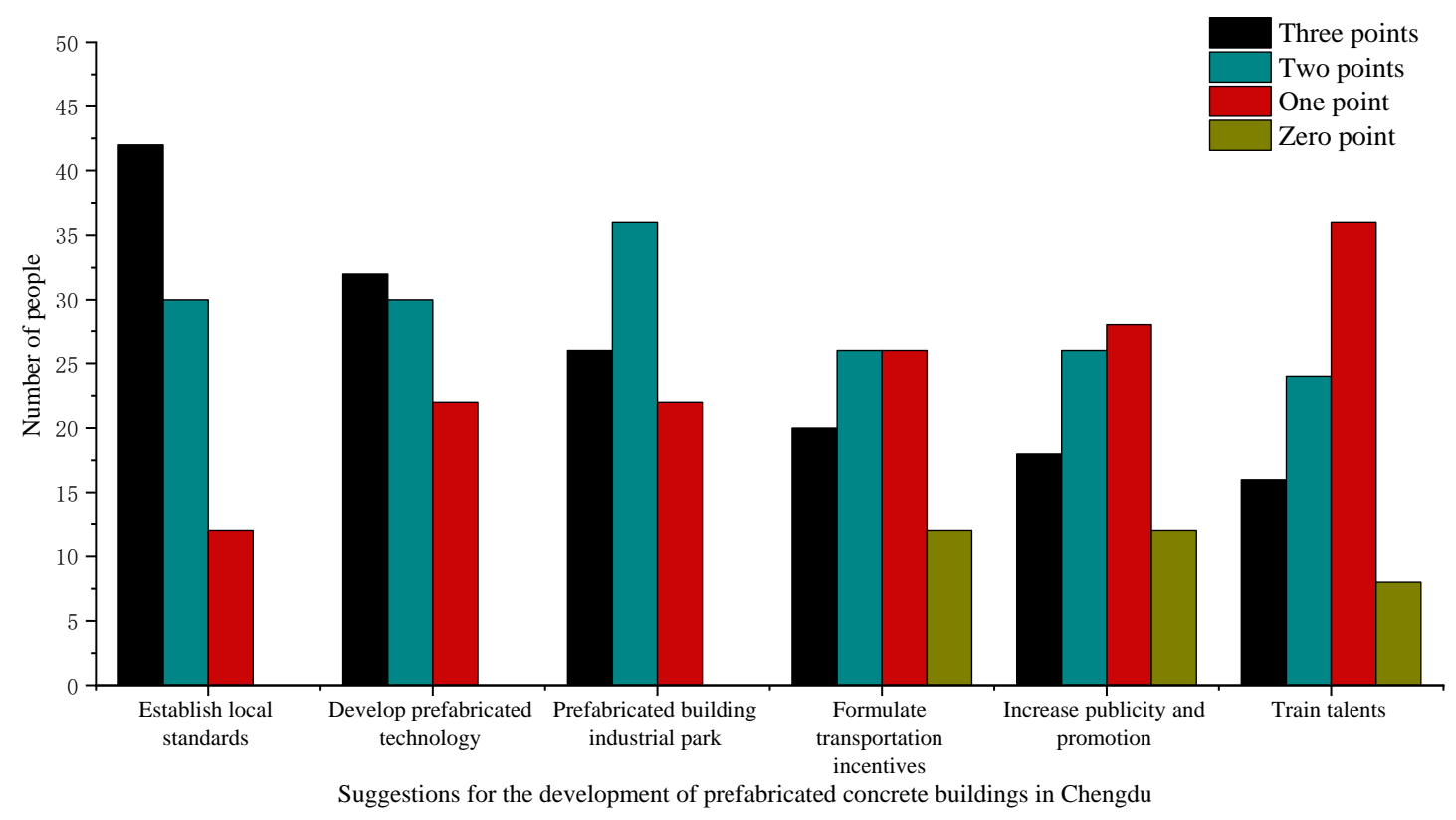

Figure 7. Score statistics of development suggestions for prefabricated concrete buildings in Chengdu

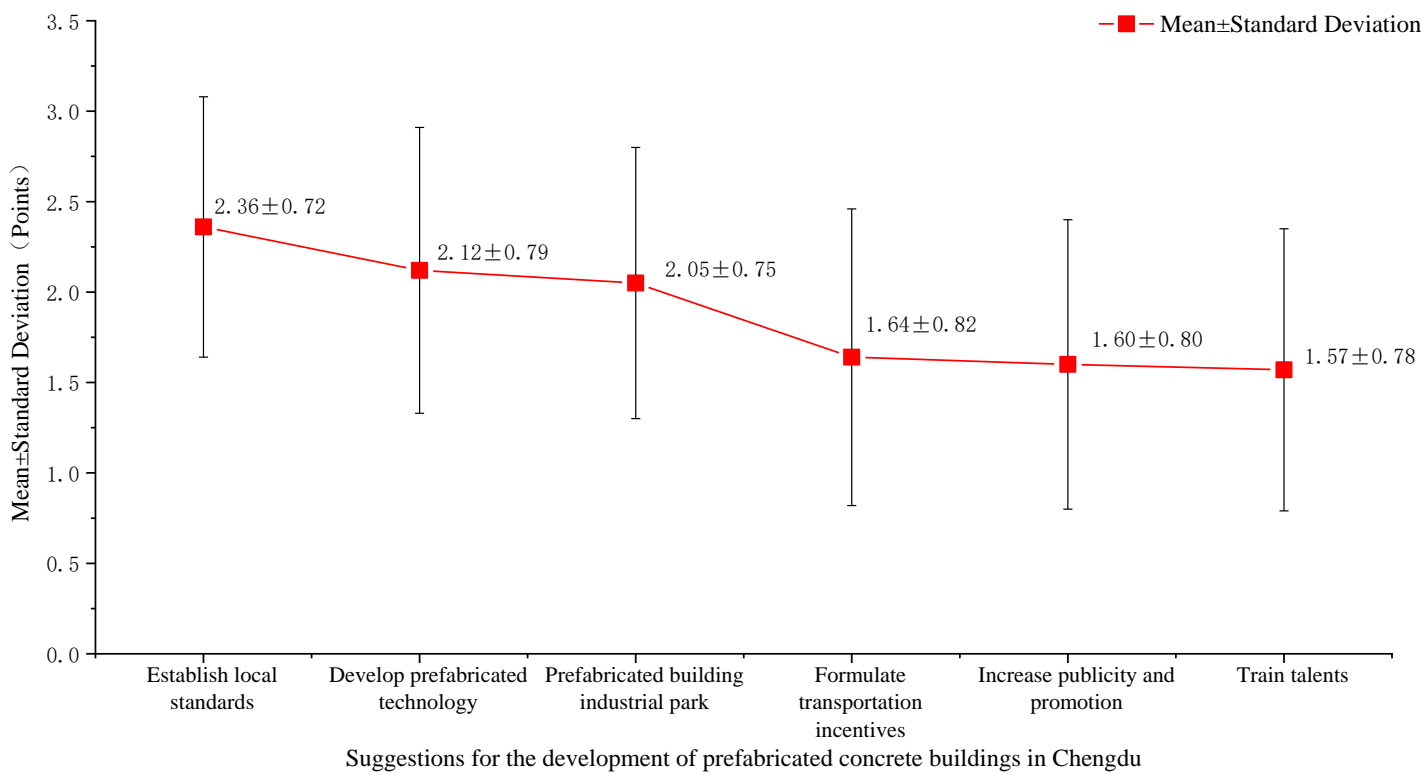

Figure 8. Mean and standard deviation of development suggestion scores

From the Figure 7 and Figure 8, it can be seen that the "establish local standards" scoring $2.36 \pm 0.72$, which is the most effective suggestion, and corresponds to the most important obstacle "imperfect specification and standard system". The Chengdu municipal government has planned to form a local standard system covering prefabricated construction design, components production, and construction quality and safety. On this basis, the government must increase 
the promotion and update in a timely manner.

"Develop prefabricated technology" scores $2.12 \pm 0.79$. Prefabricated construction started late in Chengdu. It is necessary to actively explore and introduce new technologies at home and abroad, and reasonably apply them according to actual conditions of Chengdu. The item "Establish prefabricated construction industrial parks" scores $2.05 \pm 0.75$. Five prefabricated construction industrial bases have been built in Chengdu. Based on industrial bases, guiding design enterprises, production enterprises, construction enterprises, logistics enterprises, and scientific research units to settle in and create a comprehensive industrial park.

"Formulate transportation incentives" scores $1.64 \pm 0.82$. At the symposium, some participants proposed to formulate transportation incentives, such as reducing the tolls of expressway trucks. The "increase publicity and promotion" scores $1.60 \pm 0.80$. The main purpose of strengthening publicity is to increase public confidence in the quality and safety of prefabricated construction. The "train talents" scores $1.57 \pm 0.78$, which is the lowest. Some participants suggested that in the case of imperfect prefabricate standard system, the role of training of talent teams is not obvious, so the number of trainings can be reduced and the quality of training can be improved.

\section{DISCUSSION AND CONCLUSION}

This paper has obtained the following four conclusions through the research on the status of prefabricated concrete buildings in Chengdu, the production base of components, the price of PC components, the scale of building construction, and development obstacles and suggestions.

(1) The scale and number of component production bases should be determined with reference to the projects under construction and the proposed projects. Taking the production base as the center, the radiation circle is formed with the reasonable transportation radius, so as to carry out the layout of the production base of prefabricated components. The reasonable radiation circle should cover the entire city and minimize the overlapping areas.

(2) Government departments can rationally lay out production bases to reduce transportation costs. Technical department can complete fabricate technology standards to improve mold utilization rate. With an average reduction of 1039.8 yuan $/ \mathrm{m}^{3}$ as the goal, we should control the price of prefabricated components to promote the development of prefabricated concrete buildings.

(3) The building construction area and completed area tend to be stable in Chengdu. According to the increasing trend of the proportion of prefabricated concrete buildings, it is expected that Chengdu municipal government will dynamically adjust the proportion of prefabricated concrete buildings by an increase of $8 \%-10 \%$ per year to maintain stable development status.

(4) Through the questionnaire survey, this paper evaluates the importance of the obstacles to the development of prefabricated concrete buildings in Chengdu and the expected effectiveness of the development proposals. It is found that the most serious development obstacle is that the standardization system is imperfect, and the most effective development proposal is the establishment of local standards in Chengdu.

\section{ACKNOWLEDGMENT}

This study is financially supported by the national 13th fiveyear key research and development program of China (2016YFC0701909-1), Fundamental Research Funds for the Central Universities (106112017CDJXY200009, 106112016CDJRC000101).

\section{REFERENCES}

[1] Li, Z., Shen, G.Q., Alshawi, M. (2015). Measuring the impact of prefabrication on construction waste reduction: an empirical study in China. Resources, Conservation and Recycling, 91: 27-39. https://doi.org/10.1016/j.resconrec.2014.07.013

[2] Tam, V.W.Y., Tam, C.M., Zeng, S.X., Ng, W.C.Y. (2007). Towards adoption of prefabrication in construction. Building and Environment, 42(10): 3642-3654. https://doi.org/10. 1016/j.buildenv.2006.10.003

[3] Huang, Q. (2015). Research on Housing Industrialization Development Countermeasure in Chengdu. Master Degree Thesis, Southwest Jiaotong University, Sichuan.

[4] Liu, K., Zhang, S., Su, Y. (2018). Review on management topics of prefabricated construction building. China Journal of Civil Engineering and Management, 35(6): 163-170. https://doi.org/10.13579/j.cnki.20950985.2018.06.055

[5] Ferdous, W., Bai, Y, Ngo, TD, Manalo, A., Mendis, P. (2019). New advancements, challenges and opportunities of multi-storey modular buildings - A state-of-the-art review. Engineering Structures, 183: 883-893. https://doi.org/10.1016/j.engstruct.2019.01.061

[6] Boyd, N., Khalfan, M.M.A., Maqsood, T. (2013). Offsite construction of apartment buildings. Journal of Architectural Engineering, 19: 51-57. https://doi.org/10.1061/(asce)ae.1943-5568.0000091

[7] Jin, R.Y., Gao, S., Cheshmehzangi, A., Aboagye-Nimo, E. (2018). A holistic review of off-site construction literature published between 2008 and 2018. Journal of Cleaner Production, 202: 1202-1219. https://doi.org/10.1016/j.jclepro.2018.08.195

[8] Larsson, J., Eriksson, P.E., Olofsson, T., Simonsson, P. (2014). Industrialized construction in the Swedish infrastructure sector: core elements and barriers. Construction Management and Economics, 32(1): 83-96. https://doi.org/10.1080/01446193.2013.833666

[9] Hong, J., Shen, G.Q., Li, Z., Zhang, B., Zhang, W. (2018). Barriers to promoting prefabricated construction in China: A cost-benefit analysis. Journal of Cleaner Production, 172: 649-660. https://doi.org/10.1016/j.jclepro.2017.10.171

[10] Arashpour, M., Kamat, V., Bai, Y, Wakefield, R., Abbasi, B. (2018). Optimization modeling of multi-skilled resources in prefabrication: Theorizing cost analysis of process integration in off-site construction. Automation in Construction, 95: 1-9. https://doi.org/10.1016/j.autcon.2018.07.027

[11] Innella, F, Arashpour, M., Bai, Y. (2019). Lean methodologies and techniques for modular construction: a chronological and critical review. ASCE Journal of Construction Engineering and Management, 145(12). https://doi.org/10.1061/(ASCE)CO.1943-7862.0001712 
[12] Wang, Y.H., Yu, J., Liu, J.P., Chen, Y.F. (2019). Shear Behavior of shear stud groups in precast concrete decks. Engineering Structure, 187: 73-84. https://doi.org/10.1016/j.engstruct.2019.02.002

[13] Ferdous, W., Manalo, A., Aravinthan, T., Fam, A. (2018). Flexural and shear behaviour of layered sandwich beams. Construction and Building Materials, 178: 429-442. https://doi.org/10.1016/j.conbuildmat.2018.04.068

[14] Arashpour, M., Bai, Y., Aranda-Mena, G., Bab-Hadiashar, A, Hosseini, R., Kalutara, P. (2017). Optimizing decisions in advanced manufacturing of prefabricated products: Theorizing supply chain configurations in offsite construction. Automation in Construction, 84: 146153. https://doi.org/10.1016/j.autcon.2017.08.032

[15] Xu, G.Y., Li, M., Luo, L.Z., Chen, C.H., Huang, G.Q. (2019). Cloud-based fleet management for prefabrication transportation. Enterprise Information Systems, 13(1): 87-106. https://doi.org/10.1080/17517575.2018.1455109

[16] Ferdous, W., Bai, Y., Almutairi, A.D., Satasivam, S., Jeske, J. (2018). Modular assembly of water-retaining walls using GFRP hollow profiles: Components and connection performance. Composite Structures, 194: 111. https://doi.org/10.1016/j.compstruct.2018.03.074

[17] Ferdous, W., Almutairi, A.D., Huang, Y., Bai, Y. (2018). Short-term flexural behaviour of concrete filled pultruded GFRP cellular and tubular sections with pineye connections for modular retaining wall construction. Composite $\quad$ Structures, 206: 1-10. https://doi.org/10.1016/j.compstruct.2018.08.025

[18] Ferdous, W., Manalo, A., Van Erp, G., Aravinthan, T., Ghabraie, K. (2018). Evaluation of an Innovative Composite Railway Sleeper for a Narrow-Gauge Track under Static Load. Journal of Composites for Construction, 22(2). https://doi.org/10.1061/(ASCE)CC.1943-5614.0000833

[19] Dai, H. (2017). Research on the Restrictive Factors and Countermeasures of the development of prefabricated construction in Chengdu. Master Degree Thesis, Southwest Petroleum University, Sichuan.

[20] Arif, M., Egbu, C. (2010). Making a case for offsite construction in China. Engineering, Construction and Architectural Management, 17(6): 536-548. https://doi.org/10.1108/09699981011 090170

[21] Yue, T., Mao, C., Liu, G., Wang, X. (2017). Analysis of stakeholder relationships in the industry chain of industrialized building in China. Journal of Cleaner Production,
387-398. https://doi.org/10.1016/j.jclepro.2017.03.094

[22] Chen, W., Qin, H., Tong, M. (2017). Resource scheduling for prefabricated construction based on multidimensional working areas. China Civil Engineering Journal, 50(3): $115-122$ https://doi.org/10.15951/j.tmgcxb.2017.03.014

[23] Cai, H. (2018). Research on optimization of prefabricated construction buildings based on genetic algorithm. Master Degree Thesis, Southwest Jiaotong University, Sichuan.

[24] Liu, D.S., Jiang, Q.J., Huang, Q.J., Zhao, D.W., Liu T. (2019). Research on planning and layout of prefabricated concrete component factory in national key area. China Concrete and Cement Products, 9: 60-65. https://doi.org/10.19761/j.1000-4637.2019.09.060.06

[25] Miao, Y. (2017). Application research of prefabricated concrete technology in the demonstration project in Chengdu. Master Degree Thesis, Southwest Jiaotong University, Sichuan.

[26] Mao, C., Xie, F., Hou, L., Wu, P., Wang, J., Wang, X. (2016). Cost analysis for sustainable off-site construction based on a multiple-case study in China. Habitat International, 57: 215-222. https://doi.org/10.1016/j.habitatint.2016.08.002

[27] Warszawski, A., Ishai, E. (1982). Long range planning of prefabrication industry in a national economy (summary). Building and Environment, 17(1): 47-54. https://doi.org/10.1016/ 0360-1323(82)90008-7

[28] Liao, H. (2018). Research on EPC-based cost control of the prefabricated construction. Master Degree Thesis, Southwest Jiaotong University, Sichuan.

[29] Xu, Y. (2015). Research on prefabricated construction sustainable development in China. Master Degree Thesis, Wuhan Institute of Technology, Wuhan.

[30] Cao, X., Li, X., Zhu, Y., Zhang, Z. (2015). A comparative study of environmental performance between prefabricated and traditional residential buildings in China. Journal of Cleaner Production, 109: 131-143. https://doi.org/10.1016/j.jclepro.2015.04.120

[31] Gan, X., Chang, R., Zuo, J. (2018). Barriers to the transition towards off-site construction in China: An Interpretive structural modeling approach. Journal of Cleaner Production, 197: 8-18. https://doi.org/10.1016/j.jclepro.2018.06.184

[32] Zhang, W., Lee, M.W., Jaillon, L., Poon, C. (2018). The hindrance to using prefabrication in Hong Kong's building industry. Journal of Cleaner Production, 204: 70-78. https://doi.org/ 10.1016/j.jclepro.2018.08.190 